\title{
Gender Influence on Students' Learning Preferences: An Assessment of the Learning Styles of Postgraduate Students at African International University
}

\author{
Francisca Wavinya Ngala \\ Quality Assurance Officer/Lecturer, Education Department \\ Africa International University \\ Box 2468600502 , Karen, Nairobi
}

\begin{abstract}
This paper is a write up of a study that sought to examine the relationship between gender and learning preferences of post-graduate students at Africa International University (AIU) in Nairobi, Kenya. The study employed a descriptive survey design which used crosssectional approach to data collection. The population of the study consisted of all the 397 post-graduate students at Africa International University at the time of data collection. The sample size used was made up of 199 participants from the post-graduate Diploma, Masters' level and Doctoral programmes. A questionnaire guide was the instrument used to collect information from the participants on their gender demographics and their preferences. Statistical Package for Social Sciences (SPSS) was used to analyse the data. A modified version of the Grasha - Riechmann Student Learning Style Scales (GRSLSS) was the learning style inventory that was used to measure the learning preferences. The findings revealed that gender was not significantly related to the ways Post-graduate students at Africa International University preferred to learn.
\end{abstract}

Keywords: Gender, Learning Preferences, Postgraduate Students, Teacher, Relationship, Assignments.

\section{INTRODUCTION}

Gender is a factor among others that influence learning preferences [1]. A research was done by the faculty in the department of physiology at Wayne State University School of Medicine to establish whether gender influences learning preference. The researchers administered the Visual, Auditory, Reading/Writing, Kinesthetic (VARK) questionnaire of learning preferences to first year medical students. In this research they found out that "there were no gender differences in the percentages of males and females who preferred multimodal or unimodal styles of information presentation" [1, p. 336]. But in another research Wehrwein, Lujan and Dicarlo [2, p. 153], found that that "male and female students have significantly different learning styles". Other researchers that have found gender as a factor influencing learning preferences include: Honigsfield and Dunn [3] and Zelazek [4].

The above studies show that there is need to investigate the learning preferences of males and females so as to match their learning preferences with teaching styles. There is evidence from research that there are times when learning differences occur and other times when they don't occur between the male and female. It is possible that there were other unaccounted variables such as subject matter or culture among others which could influence research results and therefore the need to investigate more on this aspect of gender and learning preferences. 
The fact that females learn differently from males is not surprising as studies have indeed confirmed that women are very different from men. According to Gilligan [5], these differences have been ignored for too long and time is now when the women perspective need to be given attention. Stonehouse [6] also presents studies that have helped highlight the woman as a distinct person from the man. Belenky and others [7] discuss women's ways of knowing as quite unique from men's ways of knowing.

\section{LITERATURE UNDERPINNING}

Over the years theories have been constructed to explain how adult learning takes place. One thing that is clear among the theorists is that adults learn in ways quite distinct from those of children. It should be noted that before the 1970s, educators of adults generally relied on psychological understandings to inform their practice. This was soon to change with the publications of Houle [8], Kidd [9] and Knowles [10,11] which prompted research and theory building efforts to be channelled to adult learning. Since then, adult educators have codified differences between adults and children into a set of principles, a model or theory but have been unsuccessful to come up with a single theory of adult learning. They have however managed to come up with several frameworks or models with each contributing something to the understanding of adult learners. So far Knowles' Andragogy remains the best effort [12, p.83].

This explains that adult learning is a field in itself with its theorists and literature. The discussion of theories concentrated on the older theories that have stood the test of time such as: Experiential learning by Dewey [13], Kolb [14], Andragogy and self-directed learning by Knowles [15], Tough [16] and Brookfield [17], Marxism and liberation pedagogy by Marx and Freire, and Transformational learning by Mezirow [18].

This does not disregard the existence of newer approaches to learning such as women ways of knowing championed by Gilligan [5] and Belenky and others [7], informal and incidental learning by Marsick and Watkins [19], context based learning by Vigotsky [20] and Jarvis [21], critical pedagogy by Habermas [22], post-modern perspectives by Faucault [23], the power of feelings by Chodorow [24]among others, and creative approaches like somatic and narrative learning which are found in current adult learning literature [25]. The older theorists identified earlier are also inclined to certain psychological and philosophical positions which were used as the basis for the discussions of the theories for the purpose of this study. These include Pragmatism, Humanism and Marxism.

Learning styles are "characteristic cognitive, affective and physiological behaviours that serve as the relatively stable indicators of how learners perceive, interact with and respond to the environment" [26]. This definition suggests that the learning style is a broader concept which not only includes cognitive styles but also includes affective and physiological styles. It is therefore a major misconception to use cognitive style as a synonym for learning style since it covers only one aspect of learning style. Messick [19] defines cognitive style as information processing habits presenting the learner's typical mode of perceiving, thinking, problem solving and remembering. This definition excludes other aspects of learning style namely affective and physiological which are crucial as the three domains are necessary in any learning process. From the above definitions, cognitive styles and learning styles are not synonymous and should not be used as such.

For the purpose of this study, the author attempted to propose a definition for learning preferences in a bid to justify the usage of the word preference as a synonym of learning styles which is common in the literature. The verb "prefer" which suggests a particular inclination to 
learning strategy is common in the literature and therefore learning preference has been used interchangeably with learning style. The author prefers to use learning preference to learning style "students were able to style-flex or use learning strategies other than their primary learning style when the subject matter demanded them to do so" [27, p. 349]. In the examining learning styles, attention is given to not only how a student learns (style) but also how he/she prefers to learn (preference). The author would also admit that preference is not as common as style in the literature and for this reason the two words were interchangeably used in this paper as they appear when cited from the literature. Earlier scholars in the modern era prefer the neat categories hence the taxonomies in learning styles but post-modern scholars break the barriers of categories and propose learning preferences which change depending on the circumstances.

Interest in learning preferences "grew out of humanistic psychology and learning theory which places greatest emphasis on the leaner as a person" [28, p. 176]. This is in recognition of individual differences in the learners which is a very important aspect in learning. It should be acknowledged that the learners are unique and this influences the ways they prefer to learn. An understanding of how learners prefer to learn in turn may influence how the instructors design courses and instructional methods to match the preferences of their learners. Research has shown that matching student's learning preferences with the teaching preferences improves performance [29].

Learning preferences of students come to mind whenever there is a discussion on individual differences among students. To realise that students are unique even in the ways they prefer to learn is a major step towards improving instructional practice. Learning preferences of university students need to be identified so as to provide teaching strategies that match those preferences for improved performance [29].

\section{MATERIALS AND METHODS}

The study focused on post-graduate students at African International University. The study design used was descriptive survey which used the cross-sectional approach to data collection. The population of the study included all the 397 post-graduate students at Africa International University at the time of data collection. The study sample was made up of 199 participants from the post-graduate Diploma, Masters' level and Doctoral programmes. Questionnaire was the instrument used to collect information from the participants on their gender demographics and learning preferences. A 5-point scale Likert scale with responses ranging from strongly disagree to strongly agree $[30,31]$ were used in the study instruments. Statistical Package for Social Sciences (SPSS) was used to analyse the collected data and regression techniques were used for correlation. A modified version of the Grasha-Riechmann Student Learning Style Scales (GRSLSS) was the learning style inventory that was used to measure the learning preferences. The gender factor formed the independent variable while learning preferences represented the dependent variable as depicted in three dimensions of; dependent/independent learning preferences.

\section{RESULTS AND DISCUSSION}

The purpose of this study was to determine the learning preferences of post- graduate students at Africa International University and how the gender factor influences such preferences. In this study, the gender representation of the respondents indicated that the majority of the respondents were males $(65.1 \%)$, while $34.9 \%$ were female. The large number of males at Africa International University could be attributed to the fact that the university mostly trains for the church and the issue of women holding key positions in the church is still debatable in many churches. Table 1 gives a summary of gender representation of the respondents. 
Table 1. Respondents' gender

\begin{tabular}{|l|l|c|c|c|}
\hline \multicolumn{2}{|c|}{} & Frequency & Percent & Valid Percent \\
\hline \multirow{3}{*}{ Valid } & Male & 108 & 63.9 & 65.1 \\
\cline { 2 - 5 } & Female & 58 & 34.3 & 34.9 \\
\cline { 2 - 5 } & Total & 166 & 98.2 & 100.0 \\
\hline \multicolumn{2}{|l|}{ No response } & 3 & 1.8 & \\
\hline \multicolumn{2}{|l|}{ Total } & 169 & 100.0 & \\
\hline
\end{tabular}

\section{The Independent/dependent Dimensions of the GRSLSS}

On the preference of students working by themselves on their assignments in course work, the study findings indicated a no relationship with the gender factor as shown in table 2.

Table 2. Gender and preference to work alone

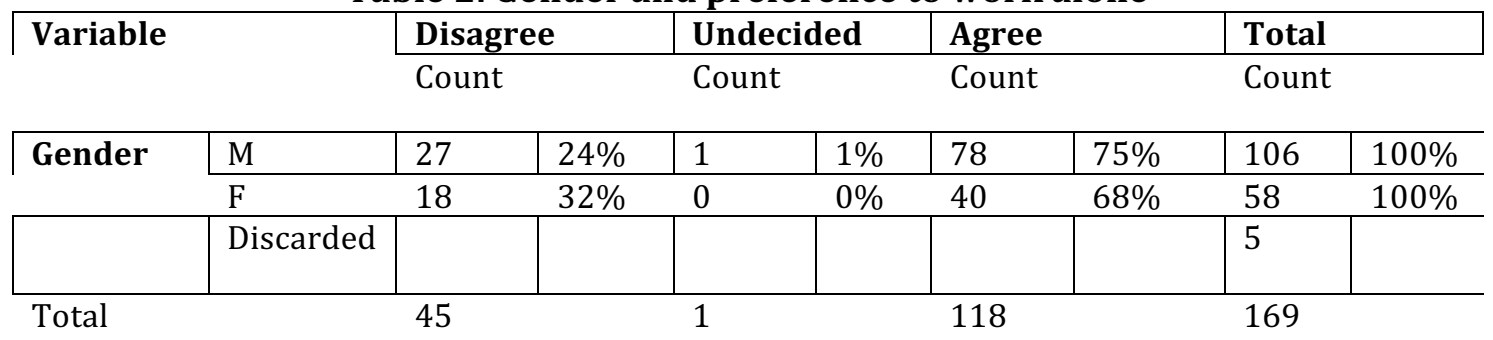

$\mathrm{R}=.058 \quad \mathrm{R}^{2}=.003 \quad$ critical value $=.950 \quad \mathrm{df}=2$ Confidence level $=0.05$

M-MaleF-Female

With regard to gender and preference to work alone, table 2 indicates that majority of the respondents, most likely preferred independent learning in doing assignments. This was demonstrated by $75 \%$ and $68 \%$ of males $(\mathrm{M})$ and females $(\mathrm{F})$, respectively.

The statistical analysis revealed an $\mathrm{R}$ value of .058, which is below the critical value of .950 at 2 $\mathrm{df}$ required to reject a hypothesis of no relationship. An $\mathrm{R}^{2}$ value of .003 indicated that only 0.3 $\%$ of the variance in preference to work alone can be accounted for by gender, which is a negligible relationship. The author therefore failed to reject the hypothesis of no relationship asserting that there is no difference, statistically, between both genders and preference to study alone in the group studied.

The author also establishes what the perceptions of the students are on studying what is important as compared to, not necessarily what the teacher says is important. The data findings are presented in table 3.

Table 3. Gender and studying what is important without teacher suggestion

\begin{tabular}{|c|c|c|c|c|c|c|c|c|c|}
\hline Variable & & \multicolumn{2}{|c|}{ Disagree } & \multicolumn{2}{|c|}{ Undecided } & \multicolumn{2}{|l|}{ Agree } & \multicolumn{2}{|c|}{ Total } \\
\hline & & Count & & Count & & Count & & Coun & \\
\hline Gender & $\mathbf{M}$ & 59 & $60.7 \%$ & 4 & $1.9 \%$ & 18 & $37 \%$ & 107 & $100 \%$ \\
\hline & $\mathbf{F}$ & 7 & $40 \%$ & 1 & $7 \%$ & 33 & $53 \%$ & 57 & $100 \%$ \\
\hline Discarded & & & & & & & & 5 & \\
\hline Total & & 66 & & 5 & & 51 & & 169 & \\
\hline
\end{tabular}

$$
\mathrm{R}=.031 \quad \mathrm{R}^{2}=.001 \quad \text { critical value }=.950 \quad \mathrm{df}=2 \quad \text { Confidence level }=0.05
$$

With regard to gender and studying what is important, table 3 shows that majority of the males were likely to prefer dependent learning in studying what is important, as shown by $60.7 \%$ 
males who failed to affirm the assertion that they study what is important without waiting for the teacher to inform them. Majority of the females were likely to prefer independent learning in studying what is important, as shown by $53 \%$ of the females who affirmed the assertion that they study what is important.

The statistical analysis produced an $\mathrm{R}$ value of .031 , which was smaller than the critical value required to reject the null hypothesis. An $\mathrm{R}^{2}$ value of .001 indicated that only $0.1 \%$ of the variance can be explained by gender which was a very small association. The hypothesis was therefore not rejected but rather it was affirmed that there is no difference, statistically, between both genders and preference to study what is important.

An inquiry was also made on the completion of required assignments as well as those that are optional. The findings on table 4 show the participants' responses.

Table 4. Gender and completing required and optional assignments

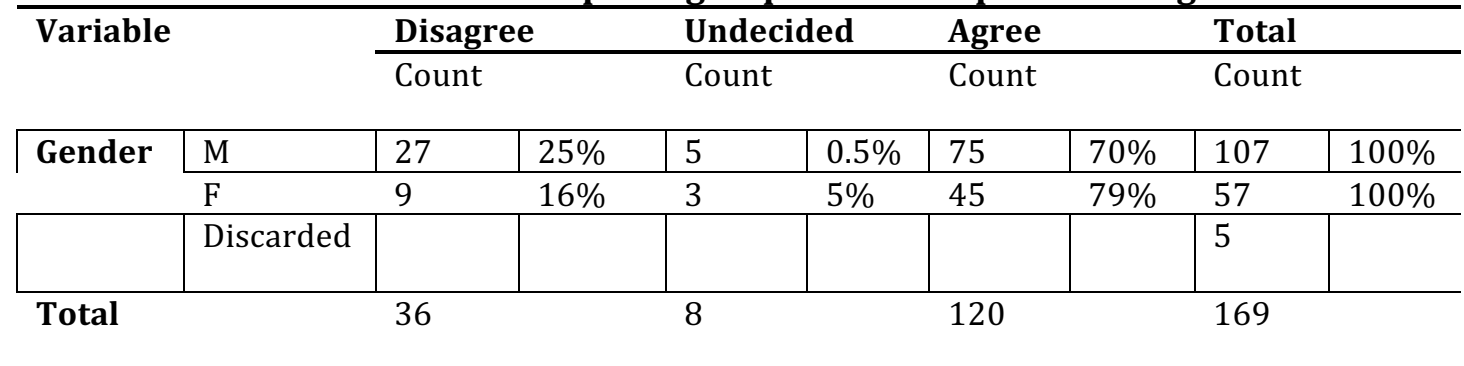

\section{$\mathrm{R}=.116 \quad \mathrm{R}^{2}=.013 \quad$ critical value $=.950 \quad \mathrm{df}=2 \quad$ Confidence level $=0.05$}

According to table 4, relating to gender and completing required and optional assignments, it was found out that the males and females were likely to prefer independent learning in relation to completing optional and required assignments. This was represented by $70 \%$ males and $79 \%$ females who affirmed the statement that they complete required and optional assignments.

The statistical analysis produced an $\mathrm{R}$ value of .116, which was smaller than the critical value required for rejecting the hypothesis of no relationship. The $\mathrm{R}^{2}$ counterpart had a value of 0.013 which showed that gender accounted for only $1.3 \%$ of the variance in completing required and optional assignments, which is a very weak relationship. This hypothesis was not rejected, but rather it was affirmed that there was no difference, statistically, between both genders and completing required and optional assignments.

A question arose on the confidence aspect and how students felt they had the ability to learn alone. The findings on table 5 record their responses.

Table 5. Gender and confidence to learn without assistance

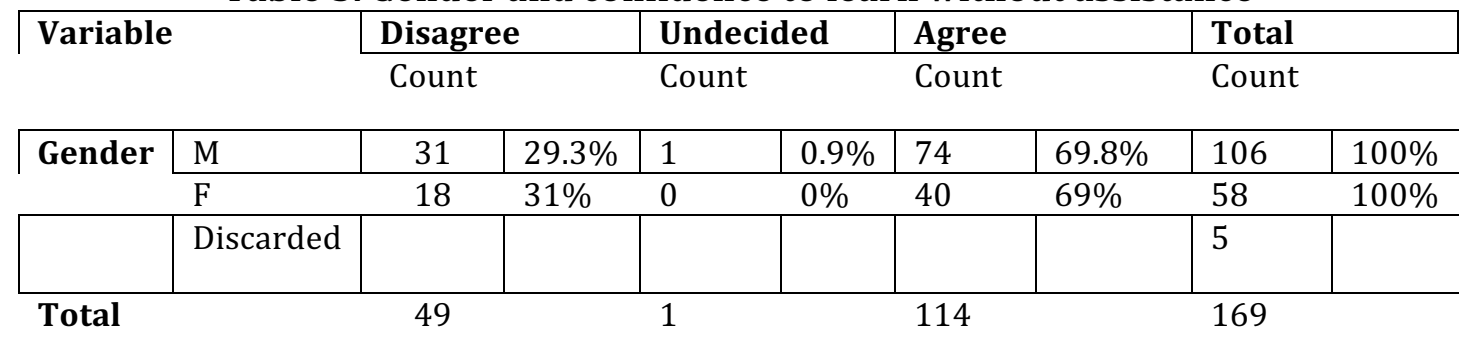

$\mathrm{R}=.021 \quad \mathrm{R}^{2}=.000 \quad$ critical value $=.950 \quad \mathrm{df}=2 \quad$ Confidence level $=0.05$ 
With regard to gender and confidence in learning, table 5 reveals that majority of male and female respondents were likely to prefer independent learning, in relation to confidence in learning. This was demonstrated by $69.8 \%$ of males $69 \%$ of females who responded favourably to the statement that they feel confident about their ability to learn on their own.

The statistical analysis revealed an $\mathrm{R}$ value of .021, which was smaller than the critical value required for rejecting the hypothesis of no relationship. An $\mathrm{R}^{2}$ value of .000 indicated that gender did not account for the variance in confidence to work, which suggests no relationship. The author consequently did not reject the hypothesis but affirmed that there was no difference, statistically, between both genders and confidence in learning.

Based on the preference to finding more on a liked topic, participants gave varied responses as shown in table 6.

Table 6. Gender and finding out more about a topic independently

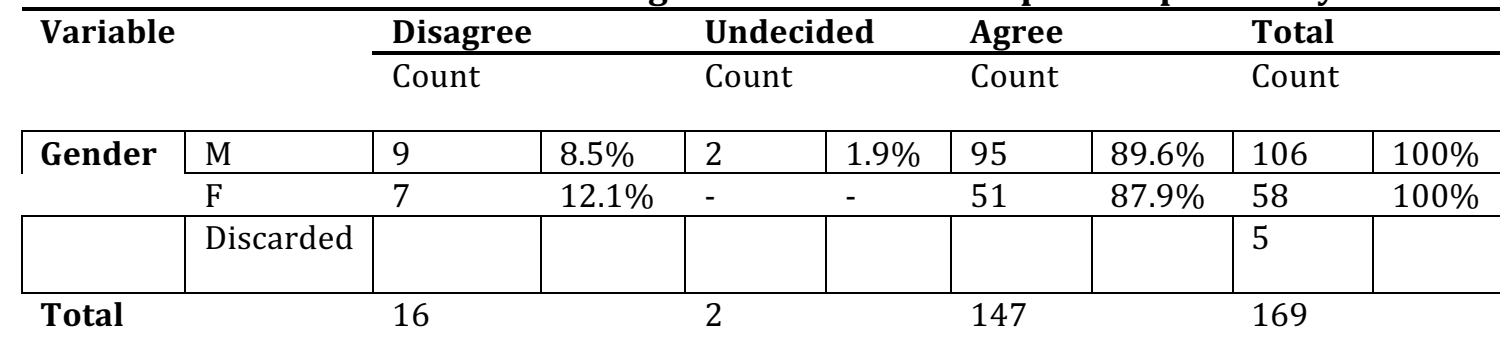

\section{$\mathrm{R}=.044 \quad \mathrm{R}^{2}=.002 \quad$ critical value $=.950 \quad \mathrm{df}=2 \quad$ Confidence level $=0.05$}

The gender of the respondents in relation to finding more about a topic as shown in table 6 indicated that majority of males and females were likely to prefer independent learning, in relation to finding more about a topic. This is reported by $89.6 \%$ males and $87.9 \%$ females who affirmed the assertion that they find more about a topic on their own.

The statistical analysis revealed an $\mathrm{R}$ value of .044, which was smaller than the critical value required for rejecting the hypothesis of no relationship. An $\mathrm{R}^{2}$ value of .002 suggested that gender can explain only $0.2 \%$ of the variance in finding out more about a topic, which suggests a very negligible relationship. The author consequently failed to reject the hypothesis and affirmed that there was no difference, statistically, between both genders and finding out more on a topic.

On whether students preferred to develop their own ideas about course content, data findings are depicted in table 7.

Table 7. Gender and developing own ideas about course content

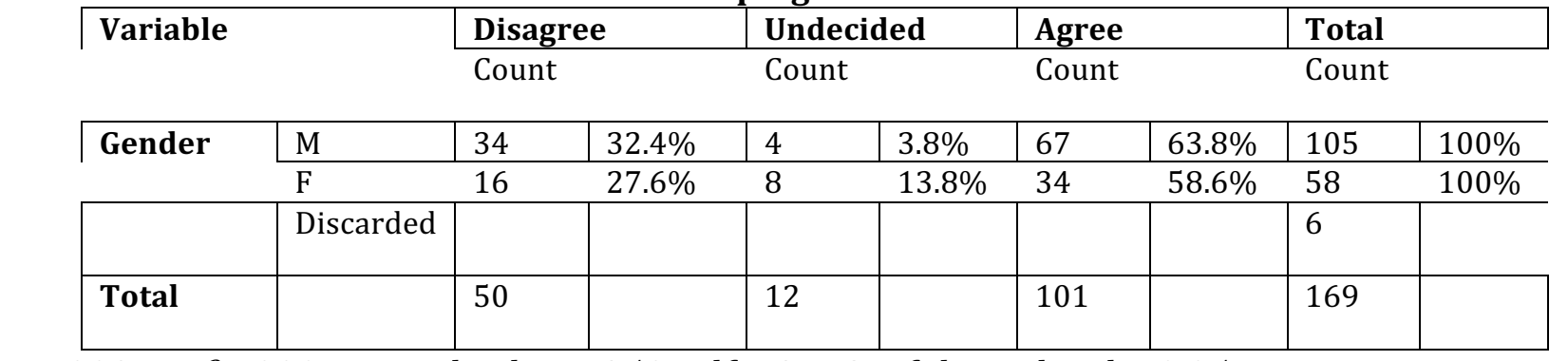

$\mathrm{R}=.003 \quad \mathrm{R}^{2}=.000 \quad$ critical value $=.950 \quad \mathrm{df}=2 \quad$ Confidence level $=0.05$ 
Concerning gender and developing own ideas about course content, table 7 shows that majority of the respondents were likely to prefer independent learning, in relation to developing own ideas about a course. It can be seen from table 7 that $63.8 \%$ of the males and $58.6 \%$ of the females affirmed the statement that they develop own ideas about course content.

The statistical analysis revealed an $\mathrm{R}$ value of .003, which was smaller than the critical value required to reject the hypothesis of no relationship. An $\mathrm{R}^{2}$ value of .000 suggested that gender does not contribute to the variance in developing own ideas about course content, which suggests no relationship. The author consequently failed to reject the hypothesis and affirmed that there was no difference, statistically, between both genders and developing own ideas about course content.

Most students prefer not to rely on teachers to tell what is important to learn as shown in table 8. The fact that students prefer to read independently is evident of their competence.

Table 8. Gender and non-reliance on teachers to tell what is important to learn

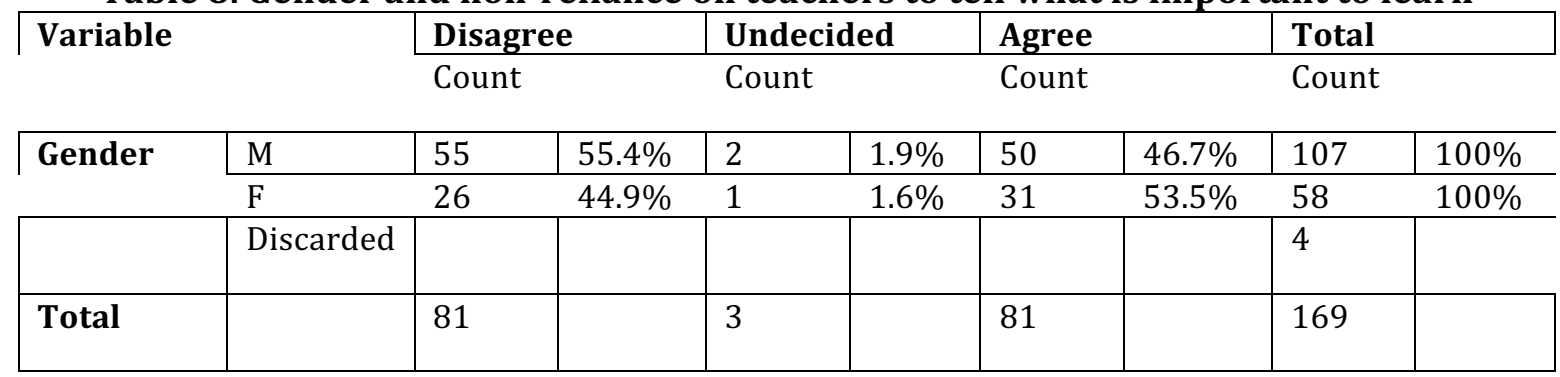

$\mathrm{R}=.051 \quad \mathrm{R}^{2}=.003 \quad$ critical value $=.950 \quad \mathrm{df}=2 \quad$ Confidence level $=0.05$

In regard to gender of the respondents and non-reliance on teachers according to table 8 , it was found out that the males were likely to prefer dependent learning, with reference to nonreliance on teachers to tell what is important, while females were likely to prefer independent learning. This was shown by $55.4 \%$ of males who failed to affirm the statement that they did not rely on teachers to tell them what is important to learn and $53.5 \%$ of females who affirmed the statement.

The statistical analysis revealed an $\mathrm{R}$ value of .051, which was smaller than the critical value required for rejecting the hypothesis of no relationship. A corresponding $\mathrm{R}^{2}$ value of .003 suggested that gender can explain only $0.3 \%$ of the variance in non-reliance on teachers to tell what is important, which showed a negligible relationship. The researcher consequently failed to reject the hypothesis and affirmed that there was no difference, statistically, between both genders and non-reliance on teachers to tell what is important.

In fulfilment of the objective, the author also sought to identify the preference for students to be told exactly what material is to be covered in exams. The findings are as sown in table 9.

Table 9. Gender and non-provision of information about material covered in exams

\begin{tabular}{|c|c|c|c|c|c|c|c|c|c|}
\hline \multirow{2}{*}{\multicolumn{2}{|c|}{ Variable }} & \multicolumn{2}{|c|}{ Disagree } & \multicolumn{2}{|c|}{ Undecided } & \multicolumn{2}{|l|}{ Agree } & \multicolumn{2}{|l|}{ Total } \\
\hline & & Count & & Count & & Count & & Count & \\
\hline Gender & $\mathrm{M}$ & 56 & $52.3 \%$ & 9 & $8.4 \%$ & 42 & $39.3 \%$ & 107 & $100 \%$ \\
\hline & $\mathrm{F}$ & 35 & $60.3 \%$ & 1 & $1.7 \%$ & 22 & $38 \%$ & 58 & $100 \%$ \\
\hline & $\begin{array}{l}\text { Discar } \\
\text { ded }\end{array}$ & & & & & & & 4 & \\
\hline Total & & 91 & & 10 & & 64 & & 169 & \\
\hline
\end{tabular}

$\mathrm{R}=.112 \quad \mathrm{R}^{2}=.012 \quad$ critical value $=.950 \quad \mathrm{df}=2 \quad$ Confidence level $=0.05$ 
In regard to gender of the respondents and not providing information about what material is covered in exams, table 9 reports that both males and females were likely to prefer dependent learning, with reference to non-provision of information about material covered in exams. Disagreement with the assertion that students should not be told what material is to be covered in exams, which showed dependent learning was represented by $52.3 \%$ and $60.3 \%$ of male and female respondents respectively.

The statistical analysis revealed an $\mathrm{R}$ value of .112, which was smaller than the critical value required for rejecting the hypothesis of no relationship. The corresponding $\mathrm{R}^{2}$ value of .012 suggested that gender can explain only $1.2 \%$ of the variance in students not being told what material is to be covered in exams, which suggests a very negligible relationship. The researcher failed to reject the hypothesis and affirmed that there was no difference, statistically, between both genders and non-provision of information about what material is covered in exams.

Preference for clear and detailed instructions on how to complete assignments was another factor that the author assessed for learning preference based on the gender of the participants. The data findings are presented in table 10.

Table 10. Gender and non-preference of clear and detailed instruction on completing assignments

\begin{tabular}{|l|l|c|c|c|c|c|c|c|c|}
\hline \multicolumn{2}{|l|}{ Variables } & \multicolumn{2}{|c|}{ Disagree } & \multicolumn{2}{c|}{ Undecided } & \multicolumn{2}{c|}{ Agree } & \multicolumn{2}{c|}{ Total } \\
\cline { 2 - 11 } & Count & & Count & & Count & & \multicolumn{2}{c|}{ Count } \\
\hline \multirow{2}{*}{ Gender } & $\mathrm{M}$ & 87 & $82 \%$ & - & - & 10 & $18 \%$ & 106 & $100 \%$ \\
\cline { 2 - 11 } & $\mathrm{F}$ & 53 & $91 \%$ & 1 & $2 \%$ & 4 & $7 \%$ & 58 & $100 \%$ \\
\hline \multirow{2}{*}{ Total } & Discarded & & & & & & & 5 & \\
\hline
\end{tabular}

$\mathrm{R}=.144 \quad \mathrm{R}^{2}=.021 \quad$ critical value $=.950 \mathrm{df}=2 \quad$ Confidence level $=0.05$

Relating gender to non-preference for clear and detailed instruction on completing assignments, Table 10 shows that both males and females were most likely to prefer dependent learning, in relation to non-preference for clear and detailed instruction on completing assignments. This is reported by $82 \%$ males and $91 \%$ females who disagreed with the assertion that they do not prefer clear and detailed instructions on how to complete assignments.

The statistical analysis revealed an $\mathrm{R}$ value of .144 , which was smaller than the critical value required to reject the hypothesis of no relationship. An $\mathrm{R}^{2}$ value of .021 suggested that gender can explain only $2.1 \%$ of the variance in non-preference for clear and detailed instruction on completing assignments, which suggests a very negligible relationship. The author consequently failed to reject the hypothesis at .05 confidence level and affirmed that there was no difference, statistically, between both genders and non-preference for clear and detailed instruction on completing assignments.

The study examined the necessity for teachers to provide course outlines and notes, findings 
Table 11.Gender and non-preference for provision of outlines and notes

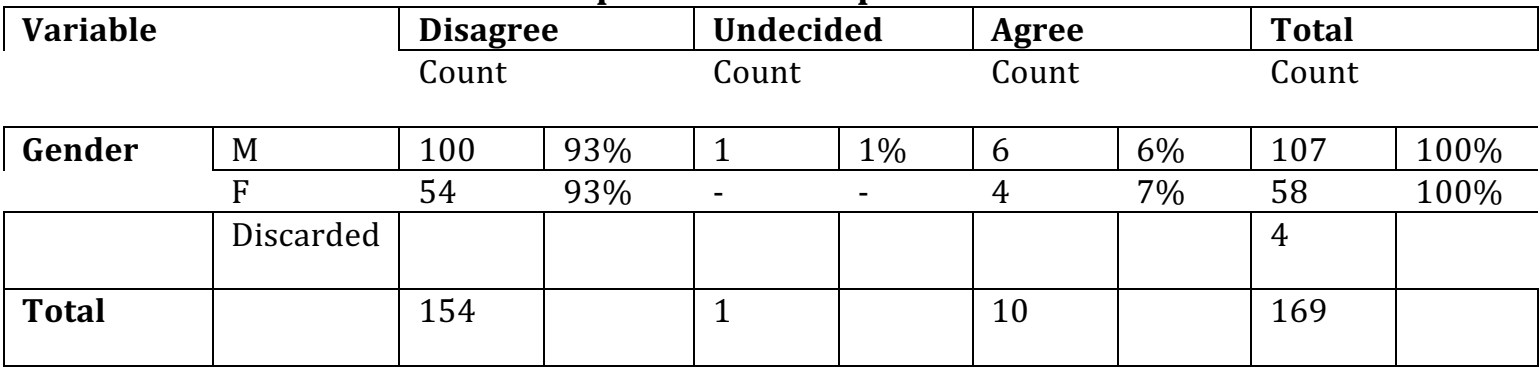

$\mathrm{R}=.038 \quad \mathrm{R}^{2}=.001 \quad$ critical value $=.950 \quad \mathrm{df}=2 \quad$ Confidence level $=0.05$

Table 11 on gender and non-preference for provision of outlines and notes, reveals that majority of males and females were likely to prefer dependent learning, in relation to nonpreference for provision of outlines and notes. This was reported by $93 \%$ of both males and females who failed to affirm the statement that they don't like teachers to provide outlines and notes.

The statistical analysis revealed an $\mathrm{R}$ value of .038, which was smaller than the critical value required for rejecting the hypothesis of no relationship. The corresponding $\mathrm{R}^{2}$ value of .001 suggested that gender can explain only $0.1 \%$ of the variance in non-preference for provision of outlines and notes, which suggests a very negligible relationship. The author based on this, fails to reject the hypothesis and affirms that there was no difference, statistically, between both genders and non-preference for provision of outlines and notes.

On whether students preferred teachers' approval before working on a class project, the study results are recorded as shown in table 12.

Table 12. Gender and non-disappointment for not getting teacher's approval before working on a project

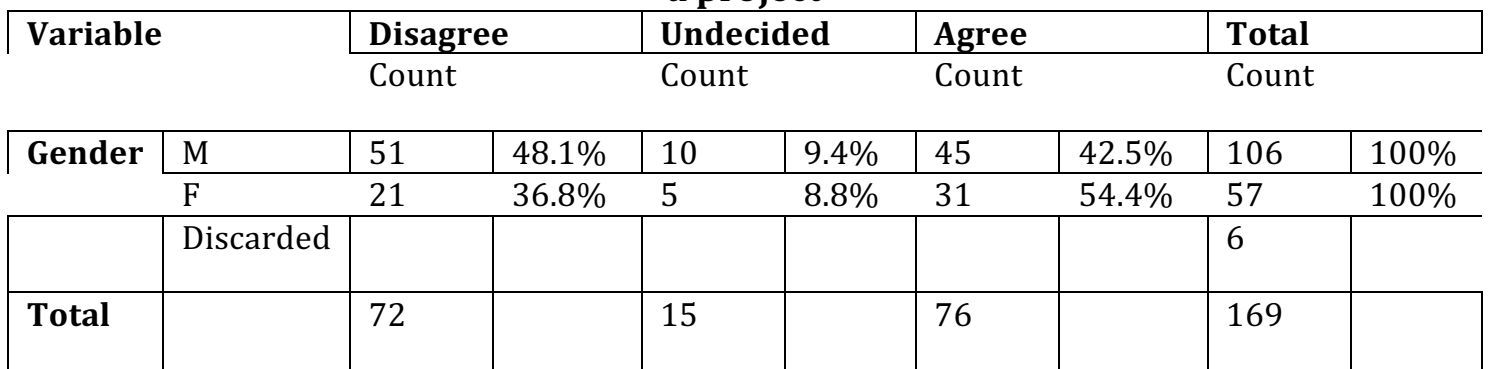

$\mathrm{R}=.117 \quad \mathrm{R}^{2}=.014 \quad$ critical value $=.950 \quad \mathrm{df}=2 \quad$ Confidence level $=0.05$

In relation to gender and non-disappointment for not getting teacher's approval before working on a project, table 12 reveals that the females were likely to prefer independent learning, with reference to non-disappointment for not getting the teacher's approval before working on a course project, as represented by $54.4 \%$ affirmation of the statement that they were not disappointed for not getting teacher's approval before working on a course project.

The statistical analysis revealed an $\mathrm{R}$ value of .117 which was smaller than the critical value required for rejecting the hypothesis of no relationship. An $\mathrm{R}^{2}$ value of .014 suggested that gender can explain only $0.14 \%$ of the variance in non-disappointment for not getting teacher's approval before working on a course project, which suggests a very negligible relationship. The authortherefore failed to reject the hypothesis and affirmed that there was no difference, statistically, between both genders and non-disappointment for not getting teacher's approval before working on a course project. 
The study also sought to find out the students close supervision by teachers on course projects and recorded the findings in table 13.

Table 13. Gender and non-preference for close teacher supervision on projects

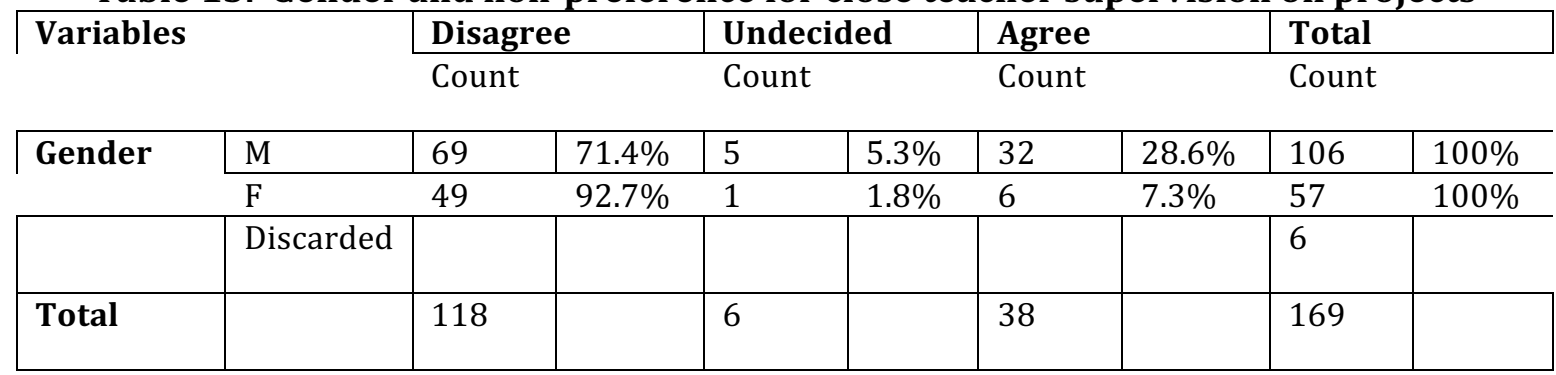

$\mathrm{R}=.155 \quad \mathrm{R}^{2}=.024 \quad$ critical value $=.950 \quad \mathrm{df}=2 \quad$ Confidence level $=0.05$

The analysis on gender, as reported in table 13, which relates gender to non-preference for close teacher supervision on projects, revealed that majority of males and females were likely to prefer dependent learning, with reference to non-preference for close teacher supervision. At least $71.4 \%$ of the males disagreed with the assertion that students should not be closely supervised by teachers on projects, while $92.7 \%$ of the females disagreed with the assertion.

The statistical analysis revealed an $\mathrm{R}$ value of .155, which was smaller than the critical value required to reject the hypothesis of no relationship. An $\mathrm{R}^{2}$ value of .024 suggested that gender can account for only $2.4 \%$ of the variance in non-preference for close teacher supervision on projects, which suggests a negligible relationship. The authortherefore failed to reject the hypothesis and affirmed that there was no difference, statistically, between both genders and non-preference for close teacher supervision on projects.

\section{CONCLUSION}

The gender of post-graduate students at Africa International University has no relationship with the ways they prefer to learn. The regression values for the univariate analyses were all less than the critical value for $\mathrm{R}$. As a result the hypothesis was not rejected at 0.05 confidence level. This means that the gender of the respondents had no significant relationship with the ways they preferred to learn. Gender is however very marginally related to learning preferences, and this cautions against categorizing certain learners.

\section{RECOMMENDATION}

Post-graduate students at Africa International University may be inclined to both independent and dependent learning preferences and therefore teaching strategies, such as group discussion, class participation, class assignments,class presentations, individual assignments, guided projects and lectures may be encouraged.Since learning styles are not permanent predispositions, learners should not be labelled or stereotyped but should be exposed to various learning strategies as their preferences will shift based on the particular learning situation.

Gender as a variable is not significantly related to learning preferences of Post-graduate students at Africa International University and therefore should not be used as a major determinant of learning preferences.

\section{References}

Slater, J. A., Lujan, H. L., \& Stephene, E. D. (2007). Does Gender Influence Learning Style Preferences of First Year Medical Students? Advances in Physiology Education, 31(4), 336-342

Wehrwein, E., Heidi A., Lujan, L., \& Stephen, E. D. (2006). Gender Differences in learning style preferences among undergraduate physiology students. Advances in Physiology Education, 31 153-

157,doi:10.1152/advan.00060.2006. 
Honigsfield, A., \& Dunn, R. (2003). High School Male and Female Learning-Style Similarities and Differences in Diverse Nations. The Journal of Educational Research, 96(4) 195-206.

Zelazek, J.R. (1986). Learning Styles, Gender, and Life Cycle Stage. Relationships with Respect to Graduate Students (Eric Document Reproduction Service No. ED 276371).

Gilligan, C. (1982). In a Different Voice: Psychological Theory and Women's Development. Cambridge: Harvard University Press.

Stonehouse, C. (1993). Learning from Gender Differences. In The Christian Strategies and Orientation. Netherlands. Kluwer Academic Publisher. Higher Student Learning Style Scales Student Learning Styles and Brain Behaviour. Students' Enjoyment Level in Distributed Environments. New Orleans, LA: Styles and Classroom Methods. American Psychologist 27 (1972), 144 - 147.

Belenky, M. F., Clinchy, B. M., Goldberger, N. R., \& Tarule, Y. M., (1986). Women's Ways of Knowing: The Development of Self, Voice and Mind. New York: Basic Books.

Kidd, J. R. (1973). How Adults Learn. New York. Association Press.

Knowles, M. S. (1970). The modern practice of adult education: Androgogy versus pedagogy. New York: New York Association Press.

Knowles, M. (1973).The Adult Learner: A Neglected Species. 3rd Edition Houston: Gulf Publishing Company.

Meriam, S., Cafferella, R., \& Baumgartner, L. M. (2006). Learning in Adulthood: A Comprehensive Guide $3^{\text {rd }}$ Edition. San Francisco: John Wiley and Sons.

Dewey, J. (1938). Experience and education. New York: Macmillan.

Kolb, D.A. (ed.)(1981). Learning Styles and Disciplinary Differences. Needham Heights, MA: Gim press.

Knowles, M. (1980). The Modern Practice of Adult Education: From Pedagogy to Andragogy. New York: Cambridge.

Tough, A. (1971).The adult's learning projects: A fresh approach to theory and practice in adult learning.

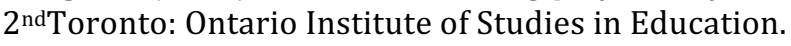

Brookfield, S. D. (1986). Understanding and Facilitating Adult Learning. San Francisco: Jossey Bass Publishers.

Mezirow, Jack. (1991). Transformative dimensions of adult learning. San Francisco: Jossey Bass Publishers.

Messick, S. (Ed.) (1979). Individuality in Learning. San Francisco: Jossey Bass.

Vygotsky, L.S. (1978). Mind in Society: The Development of Higher Psychological Processes. Cambridge: Havard University Press.

Jarvis, P. (1987). Adult Learning in the Social Context. London: Groom Helm.

Habermas, J. (1972). Knowledge and Human Interests. trans. Jeremy J. Shapiro. London: Heineman.

Foucault, M. (1980). Power/knowledge: Selected interviews and other writing. New York: Pantheon Press.

Chodorow, N. (1999). The power of feelings: Personal meaning in psychoanalysis, gender and culture. New Haven: Yale University press.

Meriam, S. B. (Ed.) (2001). The New Update on Adult Learning Theory. Number 89, Spring 2001. San Francisco: Jossey Bass.

Keefe, J. W. 1979. Student Learning Styles: Diagnosing and Prescribing Programmes. Student Learning Styles and Brain Behaviour. Reston, Virginia: National Association of Secondary Principals.

Williamson, M. F., \&Watson, R. L. (2006). Learning styles research: Understanding how teaching should be impacted by the way learners learn Part I: Understanding how learners interact with learning environments and instructional practices . CEJ: Series 3(1), 27-42.

Yount, W. (1999).Called to Teach. An Introduction to the Ministry of Teaching. Nashville Tennessee: Broadman and Holman Publishers.

Claxton, C. S., \& Murrel, P. H. (1987). Learning styles: Implications for improving education practices. ASHE-ERIC Higher education report No. 4 Washington D.C.: Association for the study of Higher Education.

Gall, M., Gall, J. P., \& Borg, W. R. (2003). Educational research: An Introduction. Boston: Pearson.

Nachmias, C. F., \&Nachmias, D. (1996).Research Methods in the Social Sciences 5th Edition. New York: St. Martins Press. 